\title{
SC|A2
}

Edúcaçã̃o, Comunicação e Tecnologia

Atribuiçãa BB CY 4.0

\section{"Minha mãe e Eu": Mulheres, Professoras e trocas educacionais em tempos de distanciamento social}

\author{
Carolina Queiroz Santana ${ }^{1}$ \\ Noemia Barreto Queiroz Santana ${ }^{2}$
}

\section{Resumo}

Este texto apresenta um relato de experiência a partir das vivências de duas mulheres professoras, mãe e filha, durante a pandemia do COVID-19. Buscamos responder o seguinte questionamento: quais condições de trabalho são colocadas as mulheres professoras, no contexto da pandemia mundial? Para isso, partimos das nossas experiências, e vivências, enquanto duas professoras, que passam por esse isolamento juntas. Tencionamos a necessidade de efetivar discussões que não apenas levem em consideração a desigualdade educacional inerente ao acesso à tecnologia, mas que também reflitam sobre as condições trabalhistas de mulheres professoras, em situação de isolamento. Por fim, destacamos que as condições colocadas ao trabalho remoto por meio de tecnologias digitais, pouco levam em conta o acúmulo da jornada de trabalho direcionado a mulher.

\section{Palavras-chave}

Mulheres Professoras. Trabalho Remoto. COVID-19.

Recebido em: 06/07/2020 Aprovado em: 10/12/2020

\footnotetext{
${ }^{1}$ Graduada em Licenciatura em Química- UFRB- Universidade Federal do Recôncavo da Bahia - Centro de Formação de Professores, interessa por pesquisas nas áreas de Ensino e História das Ciências, tendo como foco a História das Mulheres na Ciência e suas implicações para o Ensino de Ciências/Química. Cursando o Mestrado no Programa de Pós-Graduação em Ensino História e Filosofia da Ciência na Universidade Federal da Bahia e atua como Professora (Substituta) no curso de Licenciatura em Química- UFRB- Universidade Federal do Recôncavo da Bahia - Centro de Formação de Professores.

E-mail: carolinaufrb@gmail.com

2 Graduada em licenciatura em Pedagogia, possui pós-graduação em gestão educacional. Já atuou na direção e coordenação de escola da educação básica no município de Milagres-Ba. É professora da Educação Básica no mesmo município.

E-mail: noibarretoq@hotmail.com
} 


\section{"My mother and I": Women, Teachers, and educational exchanges in times of social distance}

\section{Abstract}

This text presents na experience report from the experience soft wo female teachers, mother and daughter, during the COVID-19 pandemic. We seek to answer the following question: what are the working conditions for women who are teachers in the context of the global pandemic? For that, we start from our experiences as twoteachers, who go through this isolation together. We intend to carry out discussions that not only consider the education Aline quality inherent in the Access to technology, but also reflect on the working conditions on women teachers, in a situation of isolation. Finally, we emphasize that the conditions placed on remote work by means of digital technologies, take little account of the accumulation of working hours directed at women.

\section{Keywords}

WomenTeachers. Remote Work. COVID-19 pandemic. 


\section{Introdução}

Ao longo da história foram criados padrões de feminilidade e masculinidade, que ditavam/ditam qual lugar deve ser atribuído a cada gênero. Nesse sentido, as características desejadas à função da educação condizem mais com a feminilidade. Desde o fim do século XIX, e de forma mais acentuada após a República, há um ideário brasileiro de feminização do magistério, fundamentado na tríade mulher-mãe-professora, desenvolveu-se a crença numa visão de escola que cuida, ama e educa. Essa atitude se prolongou para as décadas seguintes à proclamação da República, e juntamente com as aspirações de unidade política e a proliferação de um discurso sobre a educação colocou nas mãos das mulheres a responsabilidade de guiar a infância e moralizar os costumes (ALMEIDA, 2004).

No plano educacional, o século $\mathrm{XX}$ ofereceu maiores oportunidades educacionais para meninas e moças. $\mathrm{O}$ magistério primário, como ocupação essencialmente feminina, proporcionou às mulheres, notadamente da classe média que se alicerçou no panorama sócio-econômico do país, a principal oportunidade para ingressar no mercado de trabalho. A possibilidade de aliar ao trabalho doméstico e à maternidade, uma profissão revestida de dignidade e prestígio social fez que ser professora se tornasse extremamente popular entre as jovens [...] Por parte das mulheres, que nele viram a possibilidade de liberação econômica foi, no momento histórico inicial, a única forma encontrada para se inserirem no campo profissional, mesmo que isso representasse a aceitação da profissão envolta na aura da maternagem e da missão. A possibilidade de se profissionalizarem através do magistério primário foi um meio de as mulheres poderem vislumbrar uma chance de sustento, sem a obrigação do casamento ou a humilhação de viver da caridade alheia. (ALMEIDA, 2004, p.15)

Com o desenvolvimento de movimentos feministas, o lugar da mulher professora baseado na feminização do magistério passou a ser questionado. Buscou-se condições mais dignas de trabalho docente, bem como mais espaços para progredir em carreiras para além da educação básica. Estrategicamente, desde o século passado foram construídos democraticamente e ratificados pelo Brasil diversos documentos e tratados internacionais que versam sobre a igualdade entre os gêneros na educação. Entre eles, já na década de 1970, a Convenção sobre a Eliminação de Todas as Formas de Discriminação contra as Mulheres (1979) estabeleceu especificamente no seu artigo $10^{\circ}$ que "Os 
Estados-partes adotarão todas as medidas apropriadas para eliminar a discriminação contra a mulher, a fim de assegurar-lhe a igualdade de direitos com o homem na esfera da educação" e também para eliminar "todo conceito estereotipado dos papéis masculino e feminino em todos os níveis e em todas as formas de ensino [...]" (UNICEF, 1979).

No entanto, mesmo antes da pandemia mundial, vivíamos um momento instável no trabalho das/os professoras/es. Reformas educacionais como, a Reforma do Ensino Médio, a Base Nacional Comum Curricular, Base Nacional Comum - Formação de professores são apontadas como atenuantes da precarização do trabalho docente (SIQUEIRA,2019; RODRIGUES; PEREIRA; MOHR, 2020). Tais documentos negligenciaram qualquer recorte de gênero, não avançando em proposições de políticas educacionais contra a desigualdade. Já vivenciamos há alguns anos um contexto histórico e político, que de um lado, tem colocado em xeque a própria funcionalidade da escola e dos professores em trabalhar o saber sistematizado (MARSIGLIA, et al., 2017), e de outro traduz um tradicionalismo baseado em políticas direitistas que geram retrocessos às pesquisas sobre gênero e educação, pautadas em evidências duvidosas e discriminatórias atreladas às "ideologias de gênero" (REIS; EGGERT, 2017; MIGUEL, 2016).

Acrescenta-se a isso, desde o mês de março de 2020, o contexto da pandemia provocada pela COVID-19 e as medidas adotadas pela Organização Mundial de Saúde (OMS), bem como do próprio Ministério da Educação (MEC), no que diz respeito à suspensão das atividades presenciais, e às medidas de isolamento social. Destarte, a proposição do trabalho da educação de forma remota alerta para a acentuação de inúmeras desigualdades, inclusive de gênero. As mulheres vêm sendo expostas ainda mais a duplas ou triplas jornadas de trabalho, sendo as principais responsáveis pela educação dos filhos que também se encontram em isolamento, além do trabalho doméstico. Destacamos o trabalho de mulheres professoras, que já se encontram em jornada de trabalho remoto, ministrando aulas em plataformas digitais ou/e realizando atividades formativas e de pesquisa online. 
As novas condições sociais de trabalho, apresentam o home office, como estratégia a manter as atividades assalariadas. Atreladas aos recursos digitais, as aulas remotas já vêm sendo adotadas por municípios, estados e universidades, sendo nitidamente estimuladas pela iniciativa privada. Apesar disso, há poucas discussões que levam em conta as desigualdades de condições de acesso, não apenas sob um viés de classe social, como também de gênero e raça (SOS CORPO, 2020). Fica evidente a manipulação capitalista e patriarcal que aumenta o fosso da desigualdade pautado numa suposta democracia de acesso ao conhecimento que tem se mostrado cada vez mais burguesa (BAALBAKI, 2014).

Diante do exposto, este texto questiona: quais condições de trabalho são colocadas as mulheres professoras, no contexto da pandemia mundial do Covid19? Para isso, partimos das nossas vivências, enquanto duas professoras, mãe e filha, que passam por esse isolamento juntas. Abordamos debates que suscitaram da nossa própria experiência, bem como alguns dados de levantamentos que vêm sendo realizados por instituições de pesquisa. Tencionamos no texto a necessidade de efetivar discussões que não apenas levem em consideração a desigualdade educacional inerente ao acesso à tecnologia, mas que também reflita sobre as condições trabalhistas de mulheres professoras, em situação de isolamento. Para isso, primeiro apresentamos um relato autobiográfico sobre como nossas carreiras docentes se entrelaçam, e as formas de conhecer epistemologicamente presentes nesse texto e em nossos diálogos. Em seguida trazemos um panorama geral da condição da mulher professora no contexto da pandemia do COVID- 19.

\section{Carreiras docentes entrelaçadas}

Primeiramente, trazemos alguns apontamento sobre a construção desse "Nós" que redige o texto e que determina várias facetas, dialeticamente entrelaçadas de objetividade e subjetividade que constroem as autoras. De modo que precisamos dizer o quanto as trocas aqui relatadas constroem uma a outra em nossas singularidades. Não sabemos ao certo quem aqui escolheu ser filha ou mãe primeiro, mas percebemos o quanto essa relação tem nos formado 
enquanto mulheres, protagonistas da nossas histórias, e com foco maior aqui, professoras.

Vale ressaltar que torna se mãe nos anos de 1990, e educar uma menina/mulher, era um mistério desafiador diante de um contexto que balizava nossas escolhas e lugares de forma ainda mais acentuada que nos dias atuais. Em contrapartida, ser um filha encorajada a enfrentar os resquícios de um mundo dominado por homens, também nunca se configurou como tarefa fácil. Por isso, cabe ressaltar que antes de ser mãe e filha, nossas vivências se entrelaçam enquanto "mulher”.

Acreditamos ainda na importância do movimento de mulheres como agente revolucionário. Seja por meio de movimentos políticos encabeçados pelo feminismo, seja pela tão questionada "sororidade feminina". Ninguém é tão revolucionário na vida de uma mulher quanto outra. Historicamente, tivemos nossas vivências negadas, menos certificadas, por não atendermos a uma definição de verdade epistêmica, aos outros, era dito que não fazíamos parte da história, pois não estávamos nos grandes palcos onde está suposta história acontecia (PERROT, 1995). Enquanto isso, construíamos nossas histórias nas trocas, na porta da cozinha, nos espaços doméstico e no privado. Nossas histórias, ainda hoje não são frequentes nos livros didáticos e nas enciclopédias, e pouco se tem em repositórios digitais, mas estão bem presentes nas conversas informais, algumas vezes no mito, mas quase sempre na experiência de vida. $\mathrm{E}$ por isso, neste texto defendemos que uma epistemologia hegemônica, que cria normatividades de ciência, educação e história baseada em padrões de masculinidade não nos cabe, e reforçamos a necessidade de se pensar em epistemologias feministas, não só para reescrever nossas histórias, mas também no fortalecimento de mais oportunidades educacionais para meninas (COLLINS, 1990).

Ao nos reportarmos para a produção do conhecimento, e aos espaços para carreira de mulheres na docência e na ciência, observamos que a produção do saber, foi/é demarcada pela presença de um sujeito universal, que é, homem, branco, ocidental e de classe social favorecida. Inúmeras pressões sociais 
advindas dessas relações de poder, influenciam as normas epistêmicas de credibilidade que são utilizadas para avaliar a autoridade racional dos sujeitos em uma troca epistêmica. De acordo com Lalande (1996), epistemologia se refere a dois sentidos: ao poder e a capacidade de conhecer, ou seja, a capacidade cognoscitiva; e à filosofia das ciências, na verificação e validação do conhecimento. Concentrando-se na nesta definição, a epistemologia, diz respeito, aos tipos de inquéritos e comprovações utilizados para definir um conhecimento como verdadeiro ou falso. Nesse sentido, a epistemologia está sujeita aos jogos de poder presentes nas múltiplas determinações sociais, sendo transpassada por interesses ao buscar definições de verdades.

Ao determinar as mulheres enquanto "o outro" diante a uma sociedade pautada num sujeito masculino, Simone de Beauvoir (2019), explica que as mulheres passaram a ser negligências a atreladas a subalternidade. Assim, enquanto objeto da história, raramente sujeito, às produções do conhecimento derivados de práticas de mulheres perdem espaço. Mediante reivindicações feministas, a epistemologia feminista, não apenas tem produzido conhecimento, mas também realiza críticas contundentes ao modo dominante de produção do conhecimento, abordando debates sobre as formas de conhecer e validar o conhecimento produzido por mulheres ao longo da história (HARDING, 2004; COLLINS, 2000; GONZALEZ, 2005).

Desse modo, compete apresentar como nossas carreiras docentes se entrelaçam, formando-nos professoras e pesquisadoras, que produzem conhecimento, e defendem e validam essas epistemologias feministas, especialmente em nossa prática docente. $\mathrm{E}$ aqui dizemos que, torna-se mulher professora, ainda leiga, na década de 1990 se configurava como uma experiência muito mais árdua do que se torna uma mulher professora na segunda década do século XXI. Nessas quase três décadas que separam o início da carreira docente de mãe e filha que aqui escreve, muita coisa mudou, outras nem tanto.

Enquanto gênero, ganhamos mais espaço, temos mais representatividade e ocupamos mais lugares decisivos no cenário educacional. Apesar disso, ainda passamos por grandes dificuldades em ascender em carreiras docentes, e quanto 
mais elevado for o nível, menos estamos presentes. Ainda contamos com os olhares, que falam quais roupas, e cores de batom são adequados a uma professora, mas já aprendemos que não são esses elementos que definem nossa conduta moral e prática docente. Ainda ouvimos dos homens coisas como "mulheres deveriam ficar no pé do fogão", mas hoje não nos calamos mais diante de pais, maridos e orientadores que ditavam os lugares aos quais pertencíamos.

Nessa relação, a escola educou, criou, formou e empoderou mãe e filha. Afinal onde uma mãe professora deixaria sua filha no final da década de 1990, para ir trabalhar? E foi nesse jogo, que tantas vezes escola se tornou lar e lar se tornou escola. Essa nem sempre uma história bonita e confortável e por entender que essa experiência teve também um peso negativo, de desgaste físico e mental, defendemos e lutamos por políticas públicas, que permitam às mulheres lugares adequados para deixar suas/seus filhas/os enquanto trabalham.

Com o tempo, filha se tornou também aluna, e mãe se tornou professora. Assim, é impossível determinar nossa existência e nossa relação sem a escola. E sem dúvidas, muito por essa relação, a filha, que depois foi aluna, tornou-se também professora. Posto esse entrelaçamento dialético afetivo-profissional, nossas carreiras tem se entrelaçado, e a muito não somos somente mãe e filha, nem apenas professora e aluna, somos também colegas, professoras e pesquisadoras em educação. Nossa rede de pesquisa mistura diálogos educacionais das conversas entre o almoço e o jantar, nas curiosidades trocadas lavando a louça, nas emoções a cada vez que uma metodologia nova docente funciona ou uma criança aprende a decifrar os códigos da leitura. E de repente percebemos, que nossa história enquanto professoras têm sido construída também no espaço privado, no doméstico, lugar que por muito foi considerado como pouco politizado.

\section{Trocas educacionais em tempos de distanciamento social}

Levando em consideração o contexto da pandemia provocada pela COVID-19 e as medidas adotadas pela Organização Mundial de Saúde (OMS), bem como do 
próprio Ministério da Educação (MEC), no que diz respeito à suspensão das atividades presenciais, e a medidas de isolamento social, nos encontramos em isolamento social há mais de 3 meses. Nossos trabalhos, até o momento, não impõem medidas de aulas remotas ou qualquer outra modalidade de ensino. Apesar disso, nos encontramos com agendas cheias de reuniões remota e lives formativas.

Esse cenário tem nos proporcionado reflexões e preocupações no que cerne à precarização da educação e da docência, especialmente do trabalho de mulheres professoras, no contexto de durante e depois da pandemia. Em nossa vivência, um pouco mais confortável do que a maioria, dispomos de acesso mínimo a tecnologia, e porque não dizer "temos uma a outra", para ajudar e socorrer, nas trocas entre atividades acadêmicas e formativas online e serviços domésticos. A escrita desse trabalho vem das indagações e experiências que estão surgindo nestes últimos três meses.

A atividade da/o professor/a, demanda uma série de conformidades, que perpassam especialmente pela transmissão-assimilação de conteúdos em sala de aula (SAVIANI, 2012). Repentinamente, precisamos dar conta, do trabalho docente remoto, e ainda lidar com aspectos emocionais por meio dos relatos das mães dos alunos, áudios de saudades, vídeos e cartinhas fotografadas. O primeiro semestre do ano já se passou, e aquele aluno que já poderia estar escrevendo as primeiras palavras, ou conhecendo melhor a ciência enfrenta dificuldade para estudar e consequentemente para aprender.

Temos nos desdobrado como podemos, mas o sistema desigual permite a grupos mais favorecidos com mínimo de acessibilidade tecnológica, mais condições de aprendizagem remota. Diálogos incessantes de inúmeras vertentes vem afirmando que o ensino remoto é a melhor saída (para quem?). Apesar disso, vemos poucas ou quase nenhuma atividade formativa para preparar os/as professores/as a conviverem com essa nova realidade que se impôs.

As/os professoras/es formadas/os na era de revolução tecnológica, "nativos/as digitais", as coisas parecem relativamente mais adequadas, mas e quanto à 
professoras/es que não possuem formação básica para atuarem com estas tecnologias do ensino remoto? Percebemos as dificuldades e temos enfrentado as adversidades de forma bastante penosa, o que vemos diante de todos estes esforços é cada vez mais a acentuação da precarização do trabalho docente. No mês de abril Conselho Nacional de Educação (CNE) com a colaboração do Ministério da Educação (MEC), divulgou orientações para estados e municípios adequarem suas atividades educativas durante a pandemia em todos os níveis educativos, tais recomendações dialogam para adesão a recursos digitais. Assim, a postura do (MEC) tenciona para a retomada das atividades educativas em todos os níveis, mas não há até o momento, nenhum plano efetivo que considere as desigualdades e que seja realmente comprometido com a oferta de educação com qualidade e segurança para todos (PIRES; SANTOS; MESSEDER, 2020).

Em contrapartida, vivemos um "troca-a-troca” no ministério da educação, que causa ainda mais instabilidade para a problemática educacional. Nessa situação precária, a iniciativa privada vem impondo cada vez mais seus interesses na educação, como destacado a seguir:

[...] as orientações não consideram as desigualdades existentes no país, as condições de trabalho dos professores/as, os alunos/as, ou seja, as especificidades da escola pública e sua comunidade. Este projeto já está em curso e pode ser percebido na Base Nacional Comum Curricular (BNCC) e especificamente na reforma do Ensino Médio, pela lei (13.415/ 2017) "20\% da carga horária total no diurno e até 30\% no noturno podem ser contempladas com atividades a distância" [11] (p. 107-108). O atual governo está disponibilizando programas como o "Educação conectada" e a "Plataforma MEC de Recursos Educacionais Digitais". No caso da plataforma, percebe-se que os apoiadores são da rede privada e de grandes conglomerados da burguesia nacional e internacional[...]. (PIRES; SANTOS; MESSEDER, 2020, n.p.)

Muitas/os discentes e professoras/es da escola pública seriam drasticamente afetados por iniciativas de ensino remoto. Mas, achamos imprescindível nos ater também as condições trabalhistas atreladas a esse novo momento histórico. Mais ainda, ao recorte desigual de gênero, onde homens e mulheres vivenciam o distanciamento social de formas diferentes. De acordo com o boletim da ONUMulheres, "Gênero e covid-19 na América Latina e no Caribe: dimensões de gênero na resposta" as mulheres continuam sendo as mais afetadas pelo 
trabalho não-remunerado, principalmente em tempos de crise, além disso,em um contexto de emergência aumentam os riscos de violência contra mulheres e meninas. Este documento cita inúmeros fatores que esboçam, como no contexto de pandemia, a mulher trabalhadora vivencia um maior fragilidade, seja por assumir maior responsabilidade nos afazeres domésticos, na educação e cuidado com os filhos, seja em estarem expostas a maiores violências. De modo que, se reinventar professora, no contexto da pandemia mundial, diante de tantos atenuantes das desigualdades de gênero, parece uma tarefa quase impossível.

A atual forma de sociabilidade, capitalista, se reproduz historicamente de forma consubstancialmente patriarcal. Por meio de uma ideologia dominante, as necessidades dos sujeitos, e com maior ênfase das mulheres, pautadas na realidade concreta, não são levadas em consideração quando o que mais importa é o lucro (SOS CORPO, 2020). Assim, ao se buscar uma jornada de educação remota, influenciada principalmente pelas iniciativas privadas é fácil perceber uma romantização do trabalho em home office associado ao uso das tecnologia, que em pouco considera a realidade da mulher professora.

\begin{abstract}
Dentro da perspectiva de trabalho neoliberal, o home office imprime um regime de trabalho que é intermitente, já que estamos, a todo momento, conectadas(os) a ele, ao alcance de uma notificação de email que chega na tela do seu celular. Isso acontece quando a fronteira temporal é rompida e tempo do privado, o direito a nossa vida individual e subjetiva, é roubado pela exploração continuada do trabalho. Se o aspecto temporal foi destituído com o avanço da tecnologia, e consequentemente, da expansão do sistema capitalista, é preciso salientar que esta ampliação também aprofunda as desigualdades de gênero, raça/etnia e classe que estruturam as relações sociais. (SOS CORPO, 2020, n.p.)
\end{abstract}

Em contrapartida, dados da Pesquisa Nacional por Amostra de Domicílios PNAD 2015 estimaram que 83,7\% das crianças de menos de 4 anos que participaram da pesquisa tinham uma mulher como primeira pessoa responsável por elas (IBGE, 2017) enquanto apenas 16,3\% tinham homens como principal responsável. Dessas crianças, $46 \%$ estavam sob a responsabilidade de uma mulher 'não ocupada' e 37\% delas por mulheres ocupadas. Agora muitas dessas mulheres, também são "professoras" de seus filhos e filhas, que em parte realizam aulas remotas, assim a jornada de trabalho que era dupla se acentua cada vez mais. No caso de lares que têm um arranjo 
familiar monoparental feminino - as mães solo - este desafio é ainda mais significativo.

\begin{abstract}
A pandemia apenas escancara os desafios impostos às muitas mulheres mães que precisam trabalhar em jornadas duplas ou triplas. Para estas mulheres responsáveis pela renda familiar, a divisão sexual do trabalho, que já era desigual, tende a se agravar na quarentena. Mesmo no caso de pesquisadoras e cientistas, trabalhadoras privilegiadas em termos de garantia da renda frente à maior parcela das mulheres-mães, manter-se produtiva acadêmica-cientificamente sem comprometer a qualidade da maternagem é um desafio. Há estudos que apontam que a parentalidade ativa leva quase metade das novas mães (43\%) e quase um quarto dos novos pais (23\%) a renunciarem ao emprego em período integral depois do nascimento de filhos/as. (OLIVEIRA, 2020, p.159)
\end{abstract}

Silvia Federici (2019) ao tratar de trabalho doméstico lembra da importância de degenerificar o trabalho e de como se pode tentar alcançar a transição do trabalho afetivo do plano ontológico ao econômico.Mulheres internalizam e reproduzem práticas discriminatórias e é preciso desnaturalizar a ideias das mulheres como principais cuidadoras (OLIVEIRA, 2020). Além da marginalização feminina do trabalho no sistema produtivo capitalista, a mulher se encontra nessa estrutura familiar na qual exerce atividade doméstica e de cuidado com os filhos. Apesar disso, Gonçalves (2011) afirma que o problema da mulher não é isolado, e sim, decorrente do sistema de produção que se sustenta a partir da opressão do homem pelo próprio homem, além da alienação proveniente do sistema.

O projeto Parent in Science realizou uma pesquisa relacionada às desigualdades no trabalho remoto de professoras/es brasileiras/os. Os questionários foram respondidos por quase 15 mil cientistas, entre discentes de pós-graduação, pósdoutorandas(os) e docentes/pesquisadores. $\mathrm{Na}$ pesquisa $14,9 \%$ dos professores/pais, afirmaram estar conseguindo trabalhar de forma remota, enquanto apenas 4,1\% das professoras/mães afirmaram o mesmo. Os índices ultrapassam a maternidade e a paternidade, e enquanto $25,6 \%$ dos professores sem filhos tem conseguido desenvolver suas atividades docentes de forma remota, apenas $18,4 \%$ das professoras sem filhos consegue trabalhar remotamente (PARENT IN SCIENCE, 2020). 
No que se refere ao desenvolvimento de trabalhos de pesquisa, dos respondentes que possuem filhos $17,4 \%$ dos homens com filhos informaram estar conseguindo trabalhar remotamente, enquanto menos de $10 \%$ das mulheres em mesma situação tem tempo para trabalhar em home office. Mesmo os respondentes sem filhos, é percebida uma diferença das condições de trabalho remoto entre homens (36\%) e mulheres (32,8\%) (PARENT IN SCIENCE, 2020). Fica evidente nessa pesquisa como as mulheres mães são as mais prejudicadas pelo trabalho remoto, mas que a questão da desigualdade de gênero ultrapassa a própria maternidade.

Aparentemente a situação de isolamento também tem afetado a publicação de artigos por mulheres. Em um levantamento realizado pela Dados, revista de Ciências Sociais editada pelo Instituto de Estudos Sociais e Políticos (IESP) da Universidade do Estado do Rio de Janeiro (UERJ), por meio da análise das submissões de trabalhos enviados a sua avaliação, percebeu-se que entre $2016 \mathrm{e}$ o primeiro trimestre de 2020, a média de participação feminina nos trabalhos foi de 40,8\%. O ano de 2020 começou com o percentual de $40 \%$ nos primeiros três meses. No segundo trimestre, no entanto, foi registrada a menor proporção do período analisado, com apenas $28 \%$ de mulheres assinando artigos submetidos. Os trabalhos em que mulheres assinam como primeira ou única autora, a desigualdade é ainda maior, a média de primeiras autoras entre $2016 \mathrm{e}$ o primeiro trimestre de 2020 foi de $37 \%$, mas esse percentual caiu para $13 \%$ no trimestre atual (CANDIDO; CAMPOS, 2020).

Neste sentido, de acordo com a pesquisa da Parent in Science, há diferenças no percentual de homens e mulher que conseguiram manter seu cronograma de publicação após a pandemia. Dos respondentes, 47, 4\% da mulheres com filhos, e 56, 4\% das mulheres sem filhos realizaram suas publicações como o planejado. Em contrapartida 65,3\% dos homens com filhos e $76 \%$ dos homens sem filhos fizeram o mesmo (PARENT IN, SCIENCE, 2020).

Faz-se necessária a desconstrução de parâmetros de produtividade, que não levam em conta a situação das mulheres, mãe, professoras e pesquisadoras. Não se trata de um momento histórico para exaltar a competitividade por números e 
ascensões acadêmicas. Ainda mais que, se assim for feito, as mulheres nitidamente serão prejudicadas mediante ao acúmulo de tarefas as quais são expostas. Nas redes sociais e na academia a cobrança por "ser produtivas" escancaram nossos olhares a todos os momentos. No entanto, poucas atitudes têm sido tomadas na tentativa de balizar a discrepância em busca de mais direitos para as mulheres.

Neste sentido, acreditamos que ao invés de pensar em saídas imediatas, expondo especialmente as professoras a condições precárias de trabalho, é importante discutir e tencionar ao pensar na luta por uma educação com qualidade para a comunidade escolar, durante a quarentena. Este é um momento decisivo, que definirá as condições educacionais futuras, ainda é incerto quando poderemos retornar a sala de aula e abrandar o distanciamento social, mas até que isso ocorra é indispensável garantir o mínimo de dignidade ao trabalho educacional.

Historicamente, fala-se em mais igualdade de condições trabalhistas para as mulheres. Agora nos encontramos em um momento histórico, onde mais uma vez percebemos que apenas igualdade não é suficiente, necessitamos de equidade de gênero, ou seja, condições que permitam realizarmos nossos trabalhos de forma a conciliar com as novas demandas a que fomos expostas, respeitando nossos corpos, vivências e experiências às quais estamos associadas socialmente ou biologicamente simplesmente por ser mulher.

\section{Considerações finais}

Buscamos responder o seguinte questionamento: quais condições de trabalho são colocadas as mulheres professoras, no contexto da pandemia mundial? Ao fim desse texto, destacamos que as condições colocadas ao trabalho remoto de mulheres professoras, pouco levam em conta o acúmulo da jornada de trabalho direcionado a mulher. Assim, reinventar-se professora diante de tantas adversidades não parece ser um objetivo justo e coerente a acrescentar à vida das mulheres que já se encontram demasiadamente cansadas em suas novas rotinas. 
Acreditamos também que a precarização do trabalho da mulher professora se acentua em consonância a interesses da iniciativa privada, que visam ao lucro e apostam nos recursos tecnológicos educacionais como a única saída cabível. Pautados por um sistema patriarcal, misógino e desigual condições de equidade de gênero não vêm sendo consideradas ao repensar as formas como docência pode se desenvolver.

Para além das desigualdades de classe, que apresentam recorte direto no acesso às tecnologias, necessitamos pensar em um recorte de gênero, principalmente relacionado ao trabalho de mulheres mães docentes. Mais do que nunca, é um momento de pensar, discutir e tencionar o cenário político em busca de maior equidade de gênero, garantindo a mulheres professoras condições dignas de trabalho, mesmo que de forma remota.

\section{Referências}

ALMEIDA, Jane Soares. As professoras no século XX: as mulheres como educadoras da infância. In: CONGRESSO BRASILEIRO DE HISTÓRIA DA EDUCAÇÃO, 2., 2004, Curitiba. Anais, Curitiba, 2004.

BAALBAKI, E. C. F. E divulgação científica e o discurso da necessidade. LETRAS, v.24, n.48, p. 379-396, Santa Maria, 2014.

BEAUVOIR, Simone. O segundo sexo. Nova Fronteira, v.1, 2019.

CANDIDO, Marcia Rangel; CAMPOS, Luiz Augusto. Pandemia reduz submissões de artigos acadêmicos assinados por mulheres, Blog DADOS, 2020. Disponível em: <http://dados.iesp.uerj.br/pandemia-reduz-submissoes-demulheres/>. Acesso em: 06 de julho de 2020.

COLLINS, Patricia Hill. Black feministthought in thematrixofdomination. Black feministthought: Knowledge, consciousness, andthepoliticsofempowerment, $\mathrm{v}$. 138, p. 221-238, 1990.

FEDERICI, Silvia. O ponto zero da revolução: trabalho doméstico, reprodução e luta feminista. Tradução Coletivo Sycorax. São Paulo : Elefante, 2019

GONÇALVES, Renata. O feminismo marxista de Heleieth Saffioti. Lutas Sociais, n. 27, p. 119-131, 2011.

GONZÁLEZ, Verónica. Una introducción a losestudios sobre ciencia y género. Argumentos de Razón Técnica, 2005,(8): 43-66, 2005. 
HARDING, Sandra G. (Ed.). The feministstandpointtheoryreader: Intellectualandpoliticalcontroversies. Psychology Press, 2004.

IBGE, Coordenação de Trabalho e Rendimento. Aspectos dos cuidados das crianças de menos de 4 anos de idade: 2015. - Rio de Janeiro : IBGE, 2017

MARSIGLIA, Ana Carolina Galvão et al. A base nacional comum curricular: um novo episódio de esvaziamento da escola no Brasil. Germinal: marxismo $e$ educação em debate, v. 9, n. 1, p. 107-121, 2017.

MIGUEL, Luis Felipe. Da "doutrinação marxista" à" ideologia de gênero"-Escola Sem Partido e as leis da mordaça no parlamento brasileiro. Revista Direito $e$ Práxis, v. 7, n. 15, p. 590-621, 2016.

PARENT IN SCIENCE. PRODUTIVIDADE ACADÊMICA DURANTE A PANDEMIA: Efeitos de gênero, raça e parentalidade, 2020. Disponível em: < https://www.parentinscience.com>. Acesso em: 06 de julho de 2020.

PERROT, Michelle. Escrever uma história das mulheres: relato de uma experiência. Cadernos pagu, n. 4, p. 9-28, 1995.

PIRES,Izadora dos Santos; SANTOS, Victor Ferreira Dias; MESSEDER, Hélio da Silva -Tirando as máscaras para falar da escola pública. Site do Partido Comunista $\quad$ Brasileiro, 2020. Disponível em: <https://pcb.org.br/portal2/25557/tirando-as-mascaras-para-falar-da-escolapublica/> . Acesso em: 02 de julho de 2020.

SAVIANI D. Escola e democracia. 42a ed. Campinas: Autores Associados; 2012.

OLIVEIRA, Anita Loureiro. A espacialidade aberta e relacional do lar: a arte de conciliar maternidade, trabalho doméstico e remoto na pandemia da covid-19. Revista Tamoios, v. 16, n. 1, 2020.

ONU-MULHERES. Gênero e covid-19 na América Latina e no Caribe: dimensões de gênero na resposta. 2020. Disponível em:< http://www.onumulheres.org.br/wp-content/uploads/2020/o3/ONUMULHERES-COVID19_LAC.pdf > Acesso em: O2 de julho de 2020.

REIS, Toni; EGGERT, Edla. Ideologia de gênero: uma falácia construída sobre os planos de educação brasileiros. Educação \& Sociedade, v. 38, n. 138, p. 9-26, 2017.

RODRIGUES, Larissa Zancan; PEREIRA, Beatriz; MOHR, Adriana. O Documento "Proposta para Base Nacional Comum da Formação de Professores da Educação Básica”(BNCFP): Dez Razões para Temer e Contestar a BNCFP. Revista Brasileira De Pesquisa Em Educação Em Ciências, p. 1-39, 2020.

SIQUEIRA, Rafael Moreira. Currículo e políticas curriculares para o ensino médio e para a disciplina química no Brasil: uma análise na perspectiva 
histórico-crítica. 2019. Tese (Doutorado em ensino, história e filosofia das Ciências) - Universidade Federal da Bahia, Salvador, 2019.

SOS CORPO- Tempos modernos? Trabalho das mulheres em pandemia, 2020. Disponível em: < https://outraspalavras.net/feminismos/tempos-modernostrabalho-feminino-em-pandemia/ >. Acesso em: 02 de julho de 2020.

UNICEF - Fundo das Nações Unidas para a Infância. CONVENCAO SOBRE A ELIMINACAO DE TODAS AS FORMAS DE DISCRIMINACAO CONTRA AS MULHERES. 1979. 